\title{
COMPARATIVE STUDY OF COMPARISON OF SURGICALLY INDUCED ASTIGMATISM (SIA) BETWEEN SUPERIOR APPROACH (INCISION) AND TEMPORAL INCISION IN SMALL INCISION CATARACT SURGERY (SICS)
}

\author{
Tamojit Chatterjee1, Sandip Samaddar², Samir Kumar Bandyopadhyay3 \\ ${ }^{1}$ RMO cum Clinical Tutor, Department of Ophthalmology, Regional Institute of Ophthalmology, Medical College, Kolkata. \\ ${ }^{2}$ Assistant Professor, Department of Ophthalmology, Regional Institute of Ophthalmology, Medical College, Kolkata. \\ 3 Professor and HOD, Department of Ophthalmology, NRS Medical College and Hospital, Kolkata.
}

\section{ABSTRACT}

\section{BACKGROUND}

Cataract extraction is the largest surgical workload in the world. Goal of the modern cataract surgery is to reduce pre-operative astigmatism after operation to improve visual acuity and quality. Regarding the choice of incision location, previous studies reports that the superior incision induces greater change in corneal astigmatism (against the rule) than temporal (with the rule). With The Rule (WTR) is preferred, because it allows better uncorrected visual acuity. With The Rule (WTR) is preferred in most cases, as it frequently allows better uncorrected visual acuity. Nowadays, phacoemulsification remains the more advanced and technically superior method of cataract surgery; it is not always either from a cost purpose and its limitations of few type of cataracts. When incision is located superiorly, both gravity and eyelid blink tend to create a drag on the incision. These forces are better neutralised with temporal incision, because it is parallel to the vector of the forces. With-the-rule astigmatism induced by a temporal incision is advantageous, because most elderly patients have preoperative against-the-rule astigmatism. When incision is located superiorly, both gravity and eyelid blink tend to create a drag on the incision. These forces are better neutralised with temporal incision, because it is parallel to the vector of the forces. With-the-rule astigmatism induced by a temporal incision is advantageous, because most elderly patients have preoperative against-the-rule astigmatism.

\section{MATERIALS AND METHODS}

Subjects of the study were selected from consecutive cases of patients attending the Outpatients Departments of Ophthalmology with consideration of inclusion and exclusion criteria properly, NRS Medical College and Hospital, Kolkata from Nov. 2011 to Sept. 2012.

\section{RESULTS}

The surgically induced astigmatism in temporal SICS $(0.98 \pm 0.59)$ is much lower than superior SICS (1.45 \pm 1.24$)$ and the difference is statistically very significant (as P value is $<0.01$ ). In age wise distribution table, Surgically Induced Astigmatism (SIA) in temporal SICS is lower than superior SICS. It is clinically significant and statistically significant $(\mathrm{P}$ value $<0.05)$ in all age groups except in $<40$ yrs. In superior SICS male vs female, difference in SIA is statistically insignificant ( $p$ value $>0.05$ ) and in temporal SICS difference is also statistically insignificant, ( $p$ value $>0.05$ ), hence the value is independent on gender factor.

\section{CONCLUSION}

The age wise distribution and comparison table between patients undergoing superior and temporal SICS found that the temporal approach SICS gives less surgically induced astigmatism in all age groups and it is statistically significant ( $p$ value) in all groups (except in the age group < 40 yrs.). But as the sample is very small compared to other age groups, so anything cannot be concluded. So overall the study found that the surgically induced astigmatism in temporal SICS is lower than superior SICS and it is statistically significant.

\section{KEYWORDS}

With the Rule (WTR), The Surgically Induced Astigmatism (SIA), Small Incision Cataract Surgery (SICS).

HOW TO CITE THIS ARTICLE: Chatterjee T, Samaddar S, Bandyopadhyay SK. Comparative study of comparison of surgically induced astigmatism (SIA) between superior approach (incision) and temporal incision in small incision cataract surgery (SICS). J. Evolution Med. Dent. Sci. 2017;6(13):1037-1039, DOI: 10.14260/Jemds/2017/222

\section{BACKGROUND}

Cataract extraction constitutes the largest surgical workload in ophthalmological units throughout the world. In improving visual acuity, one of the goals of modern cataract surgery is to reduce pre-operative astigmatism (PEA) and comparison of

Financial or Other, Competing Interest: None.

Submission 04-01-2017, Peer Review 27-01-2017,

Acceptance 03-02-2017, Published 13-02-2017.

Corresponding Author:

Dr. Sandip Samaddar,

\#25, Sarat Chandra Road,

East Barisha, Kolkata-08.

E-mail: drsandipsamaddar@gmail.com

DOI: $10.14260 /$ jemds $/ 2017 / 222$

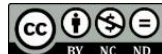

post-operative astigmatism, a factor that may reduce visual acuity and affect the quality of vision. ${ }^{1}$

Regarding the choice of incision location, previous studies reported that the superior incision induces greater change in corneal astigmatism (against the rule) than temporal (with the rule). ${ }^{2-4}$

With the rule (WTR) is preferred in most cases, as it frequently allows better uncorrected visual acuity. ${ }^{5}$

Nowadays, phacoemulsification remains the more advanced and technically superior method of cataract surgery; it is not always either from a cost purpose and its limitations of few type of cataracts. ${ }^{6}$

Many of the poor outcome is due to uncorrected refractive error. This can be reduced by the use of IOL, but 
residual refractive error, particularly post-operative astigmatism remains a problem. ${ }^{7,8}$ The temporal incision is farthest from the visual axis and any flattening due to wound is less likely to affect the corneal curvature at the visual axis. When incision is located superiorly, both gravity and eyelid blink tend to create a drag on the incision. These forces are better neutralised with temporal incision, because it is parallel to the vector of the forces. With-the-rule astigmatism induced by a temporal incision is advantageous, because most elderly patients have preoperative against-the-rule astigmatism. $^{9}$

\section{MATERIALS AND METHODS}

Subjects of the study were selected from consecutive cases of patients attending the Outpatients Departments of Ophthalmology with consideration of Inclusion and Exclusion criteria properly, NRS Medical College and Hospital, Kolkata from Nov. 2011 to Sept. 2012.

\section{Inclusion Criteria}

\section{The Criteria for Selection are as follows}

Any Age of Cataract

a) Significant senile cataract (nuclear sclerosis up to Grade III).

b) Advanced cortical cataract in both eyes.

\section{Exclusion Criteria}

a) Very hard cataract (nuclear sclerosis Grade 4).

b) Pre-existing corneal opacities, macular disorder and optic nerve disease.

c) Previous ocular surgery (trabeculectomy, refractive surgery or retinal detachment surgery).

d) Complicated cataract.

e) History of globe rupture.

f) Traumatic cataract and pseudoexfoliation syndrome.

g) Presence of pterygium.

h) Paediatric cataract.

On the basis of these criteria, total 1000 cases are selected. Out of it 500 cases are selected for superior SICS and 500 cases are selected for temporal SICS and these 500 cases include 274 male and 226 female in the superior group and 269 in male and 231 are female in temporal SICS.

So these patients were divided into two main groups.

Group 1 - Undergoing superior SICS with $6.5 \mathrm{~mm}$ frown incision.

Group 2 - Undergoing temporal SICS with $6.5 \mathrm{~mm}$ frown incision.

These two groups are then subdivided into age wise four groups.

1) Age $<40$ Yrs.

2) Age $40-55$ Yrs.

3) Age $55-70$ Yrs.

4) Age $>70$ Yrs.

\section{Preoperative Investigation}

Routine preoperative conjunctival swab for culture and sensitivity was not done, as all patients were subjected to topical-antibiotic prophylaxis from 1 week before surgery.

Blood pressure check-up.

Post-prandial blood sugar estimation.

\section{A Scan Biometry}

To calculate the power of IOL to be implanted, a scan biometry is mandatory. Biometry usually consists of keratometry reading together with an ultrasonic measurement of the axial length of the eye. Biometric information is fed into the Modified SRK 2 formula to calculate the IOL power.

\section{Measurements and Calculations of the Parameters used} in the Study

\section{Preoperative Corneal Astigmatism}

Preoperative corneal astigmatism represents the corneal toricity prior to surgery. This is measured in $\mathrm{Kv}$ (in vertical meridian) and Kh (in horizontal meridian). This is measured by preoperative keratometry.

\section{Post-Operative Corneal Astigmatism 8 Weeks after Surgery}

Represents the corneal toricity 8 weeks after surgery. This was measured by keratometry in 8th post-operative week.

\section{Surgically Induced Astigmatism (SIA) 8 Weeks after Surgery}

The Surgically Induced Astigmatism (SIA) is measured by the help of SIA Calculator version 2.1. The SIA is calculated by putting the value of $\mathrm{Kv}$ and $\mathrm{Kh}$ preoperative and postoperative in the table and we get the keratometric SIA. This calculator is authored by Dr. Saurabh Sawhney and Dr. Ashima Agarwal. 10

\section{Statistical Analysis}

This was done by calculating the $\mathrm{P}$ value for the difference between means and calculation of standard deviation. The analysis are done with the help of WINPEPI Software and SPSS 10.0 statistical analysis software.

\section{ANALYSIS AND RESULTS}

\begin{tabular}{|c|c|}
\hline Incision & Surgically Induced Astigmatism \\
\hline Superior (500) & $1.45 \pm 1.24$ \\
\hline Temporal (500) & $0.98 \pm 0.59$ \\
\hline
\end{tabular}

Comparison of Male vs Female PTs in Superior SICS

\begin{tabular}{|c|c|}
\hline Male: 274 & $1.43 \pm 1.32$ \\
\hline Female: 226 & $1.47 \pm 1.13$ \\
\hline \multicolumn{2}{|c|}{ Superior Male vs Female } \\
\hline
\end{tabular}

\begin{tabular}{|c|c|}
\hline Male: 269 & $0.98 \pm 0.63$ \\
\hline Female: 231 & $0.98 \pm 0.55$ \\
\hline \multicolumn{2}{|c|}{ Temporal Male vs Female } \\
\hline
\end{tabular}

\begin{tabular}{|c|c|c|c|c|c|l|}
\hline $\begin{array}{c}\text { Patients } \\
\text { (SUP) }\end{array}$ & $\begin{array}{c}\text { Patients } \\
\text { (TEMP) }\end{array}$ & Age & $\begin{array}{c}\text { Value } \\
\text { (SUP) }\end{array}$ & $\begin{array}{c}\text { Value } \\
\text { (TEMP) }\end{array}$ & $\begin{array}{c}\text { P- } \\
\text { Value }\end{array}$ & Significance \\
\hline 15 & 30 & $<40$ & $\begin{array}{c}1.36 \pm \\
1.07\end{array}$ & $\begin{array}{c}1.22+- \\
0.99\end{array}$ & 0.665 & Insignificant \\
\hline 150 & 185 & $\begin{array}{c}40- \\
55\end{array}$ & $\begin{array}{c}1.61+- \\
1.55\end{array}$ & $\begin{array}{c}0.96+- \\
0.56\end{array}$ & 0.00 & Significant \\
\hline 250 & 230 & $\begin{array}{c}55- \\
70\end{array}$ & $\begin{array}{c}1.37+- \\
1.08\end{array}$ & $\begin{array}{c}0.94+- \\
0.54\end{array}$ & 0.00 & Significant \\
\hline 85 & 55 & $>70$ & $\begin{array}{c}1.41+- \\
1.1\end{array}$ & $\begin{array}{c}1.08+- \\
0.59\end{array}$ & 0.043 & Significant \\
\hline \multicolumn{6}{|c|}{ Age Wise Distribution and Comparison Table } \\
of the Patients Undergoing SICS in \\
Superior vs Temporal Approach \\
\hline \multicolumn{7}{|c|}{}
\end{tabular}




\section{ANALYSIS AND RESULT}

1. The surgically induced astigmatism in temporal SICS $(0.98 \pm 0.59)$ is much lower than superior SICS $(1.45 \pm$ $1.24)$ and the difference is statistically very significant (as $\mathrm{p}$ value is $<0.01$ ).

2. In age wise distribution table, Surgically Induced Astigmatism (SIA) in temporal SICS is lower than superior SICS and the difference of surgically induced astigmatism is clinically significant and statistically significant ( $p$ value $<0.05$ ) in all age group except in $<40$ yrs.

3. In age $<40$ yrs., the total sample size is very low compared to other age group.

4. In superior SICS male vs female, difference in SIA is statistically insignificant ( $p$ value $>0.05$ ) and in temporal SICS difference is also statistically insignificant ( $\mathrm{p}$ value $>$ 0.05 ), hence the value is independent on gender factor.

\section{DISCUSSION}

The comparative study of Surgically Induced Astigmatism (SIA) between superior and temporal small incision cataract surgery was performed at NRS Medical College and total study population includes total 1000 patients and is divided into two groups for Superior and Temporal in 500 patients in each group. Each group is again subdivided according to different ages and the mean SIA and standard deviation is calculated. The SIA is basically corneal astigmatism and the preoperative $\mathrm{k}_{\mathrm{v}}$ and $\mathrm{K}_{\mathrm{h}}$ is measured before operation and postoperative $k_{v}$ and $K_{h}$ is also measured 8 weeks after the operation. The measurement is mainly done with the help of Bausch and Laumb Keratometer. The value is then put on SIA calculator version 2.1 and the resultant SIA is found.

The mean SIA values of superior and temporal SICS is calculated with standard deviation and compared. It is found that the surgically induced astigmatism in temporal SICS $(0.98 \pm 0.59)$ is lower than superior SICS $(1.45 \pm 1.24)$ and the difference is statistically very significant (as $\mathrm{p}$ value $<0.01$ ).

The population undergoing superior SICS is 500 and is divided into male (274) and female (226). The population undergoing temporal SICS is also divided into male (269) and female (231). The population is again subdivided according to ages.

The patients undergoing superior and temporal SICS is compared statistically in both male and female patients and it was found that in superior SICS the male patients, the SIA is $(1.43 \pm 1.32)$ and in female patients the SIA is $(1.47 \pm 1.13)$. In case of temporal SICS, the value of SIA is (0.98 \pm 0.63$)$ in case of male and $(0.98 \pm 0.55)$ in case of female. In both the cases the values are statistically insignificant ( $p$ value $>0.05$ ).

The age wise distribution and comparison table between patients undergoing superior and temporal SICS found that the temporal approach SICS gives less surgically induced astigmatism in all age groups and it is statistically significant ( $\mathrm{p}$ value) in all groups (except in the age group $<40 \mathrm{yrs}$.).
But as the sample were very small compared to other age groups, so anything cannot be concluded.

So overall the study found that the surgically induced astigmatism in temporal SICS is lower than superior SICS and it is statistically significant.

\section{CONCLUSION}

The age wise distribution and comparison table between patients undergoing superior and temporal SICS found that the temporal approach SICS gives less surgically-induced astigmatism in all age groups and it is statistically significant (p - value) in all groups (except in the age group $<40$ yrs.) But as the sample was very small compared to other age group, so anything cannot be concluded. So overall, the study found that the surgically-induced astigmatism in temporal SICS is lower than superior SICS and it is statistically significant.

\section{REFERENCES}

[1] Beltrame G, Salvetal ML, Chizzolini M, et al. Corneal topographic changes induced by different oblique cataract incisions. Journal Cataract Refraction surgery 2001;27(5):720-7.

[2] Joo CK, Han HK, Kim JH. Computer-Assisted videokeratography to measure changes in astigmatism induced by sutureless cataract surgery. J Cataract Refract Surg 1997;23(4):555-61.

[3] Mendívil A. Comparative study of astigmatism through superior and lateral small incisions. Eur J Ophthalmol 1996;6(4):389-92.

[4] Richard LL. Cataract surgery and lens implantation: commentary. Curr Opin Ophthalmology 1994;5:1-4.

[5] Bradbury JA, Hillman JS, Cassells-Brown A. Optimal postoperative refraction for good unaided near and distance vision with monofocal intraocular lenses. $\mathrm{Br} \mathrm{J}$ Ophthalmol 1992;76(5):300-2.

[6] Sachdeva V, Malik KPS, Bajaj S, et al. Prospective study of early postoperative corneal astigmatic changes following nonphaco SICS and clear corneal temporal incision phaco, AIOC proceedings 2006.

[7] Limburg H, Kumar R. Follow up study of blindness attributed to cataract in Karnataka, India. Ophthalmology epidemiol 1998;5(4):211-23.

[8] Singh AJ, Garner D, Floyd K. Cost-effectiveness of public funded options for cataract surgery in Mysore, India. Lancet 2000;355(9199):180-4.

[9] Gohkale NS, Sawhney S. Reduction in astigmatism in manual small incision cataract surgery through change of incision site. IJO 2005;53(3):201-3.

[10] Bidaye UA, Bidaye SU. Small incision nonphaco cataract surgery. $2^{\text {nd }}$ edn. LC Dutta: modern ophthamology, Vol: 1. Jaypee Bros, New Delhi 2000: p 34. 